\title{
Pharmacokinetics/pharmacodynamics consideration in treating critically septic patients and correlates of bacterial killing: a review article
}

\section{Abstract}

Critically septic patients carry high mortality; however, it may be ameliorated to some extent by the appropriate prescription of antimicrobials and appropriate dosing strategy. Drug metabolism in critically septic patients differ from other less critical patients, and antimicrobial treatment need to be adjusted to prevent under dosing. The augmented clearance, acute kidney injury, microvascular ischemia, all affect antimicrobials' levels. Methods of antimicrobial administration were explored, continuous infusion versus intermittent bolus, with the aim of maximizing drug exposure, hitherto, apart from PK/PD advantage, it was not translated clearly into patients' clinical outcome. Biofilms have a unique management as they need elevated antimicrobial dosages to assure adequate drug exposure, and agents that work directly on biofilms to assure its disruption. Application of PK/PD knowledge in the management of critically septic patients maximize the clinical outcome and assures proper drug exposure, avoiding under dosing and drug toxicity, and decreasing the chance of antimicrobials mutant's selection, and therapy failures.

\section{Keywords}

Antimicrobials; Dosing Strategy; Drug Toxicity; Septic Patients.

\section{Jamal Wadi MD, FIDSA ${ }^{1}$}

1 The Medical Center, Jordan Hospital
and Medical Center. 29 Adeeb Wahbah
Street. Amman, Jordan 1118.

Contact information:

Jamal Wadi.

इ" jamalwadimd@yahoo.com

\section{Introduction}

The prevalence of infection in ICU is high,bearing in mind both admitted patients with sepsis and those who acquire new ICU-related nosocomial sepsis, but the latter is noted to be associated with higher mortality despite similar severity scores [1, 2]. The incidence and 
prevalence of sepsis increase with age, the older age groups carry higher incidence and it is increased $>100$-fold $(0.2 / 1,000$ in children to $26.2 / 1,000$ in patients $>85$ years old), also, hospital mortality increases with age, from $10 \%$ in children to $38.4 \%$ in those $>85$ years old [3], with an average mortality of $37.5 \%$ in critically septic patients, and if combined with renal replacement therapy mortality reaches up to $50 \%[4,5]$. Furthermore, sepsis prevalence increased in the last few decades, a USA study identified about 8.5 million patients and found significant increase in sepsis prevalence from 1993 to 2003, and the percentage of severe sepsis (among all sepsis cases) increased continuously from $25.6 \%$ in 1993 to $43.8 \%$ in 2003 ( $p<.001$ ), age adjusted mortality rates increased whereashospital case fatality rate fell from 45.8 - 37.8\% $(p<.001)[6,7]$.

The rapid management of sepsis is crucial in the first 6 hours, and mortality increases in hourly delays even within the first 6 hours time frame, especially in patients with higher severity scores [8], hourly delay in antibiotic administration will cause mortality: $0.3 \%$ ( $P=0.04)$ for sepsis; $0.4 \%(P=0.02)$ for severe sepsis; and 1.8\% ( $P=0.001)$ for septic shock [9]. Septic patients are mostly being treated empirically before the availability of microbiological diagnosis. Appropriate antimicrobial use and attention to patients'details leads to a better early goal directed antimicrobial therapy. The empiric and appropriate use of antimicrobials contributes to decrease mortality in critically septic patients, the initial evaluation of patients, the knowledge of sepsis source is crucial to the design of the antimicrobial therapeutic intervention, and availability of surveillance data is important whether sepsis origin is SSTI, lungs, urinary or other sources. Furthermore, primary bacteremia disposes a remarkable decrease in survival in case of inappropriate antimicrobial therapy when compared with sepsis of urinary origin $[10,11,12,13]$.

\section{PK/PD effects on dosing strategies}

Many Factors may hamper antimicrobials' exposure in critically septic patients, often they have capillary leak that increases the volume of distribution $(\mathrm{Vd})$, augments renal clearance and alters protein bindings. All these factors may compromise antimicrobial blood levels, and decrease the antimicrobials exposure. However, end stage septic patients with organs failure or multi-organ dysfunction syndrome (MODS) demonstrate decreased clearance, and alerting high drug levels may be attained [14]. On the other hand, attention must be paid for the development of acute kidney injury (AKI), which is not uncommon in it affects septic patients of various severity scores, it affects about $10 \%$ of admitted septic patients, and it has an impact on antimicrobials blood levels, and exposure. [15].

Optimization of antimicrobial therapy in critically septic patients, keeping in mind safety, efficacy, avoiding suboptimal drug levels, and elevated toxic levels, by observing kidney function among other factors, then customizing doses. Here, therapeutic drug monitoring (TDM) are needed, especially in antimicrobial agents with narrow therapeutic in$\operatorname{dex}(\mathrm{TI})$, (Figure 1) $[16,17]$. $\beta$-lactam antimicrobial agents need to be adjusted mostly based on clearance, and calculated body weight, as their $\mathrm{TI}$ is wide. Nevertheless, even $\beta$-lactams antimicrobials are subjected to TDM in many parts of the world to assure drug exposure, though no clear clinical benefits of $\beta$-lactam TDM was evident outside the critically septic patients [18]

Bacterial killing is highly dependent on the susceptibility break points, minimum inhibitory concentration (MIC). However, incorporating PK/PD principles to the MIC is crucial in the understanding of the differences of bacterial killings for different antimicrobials, doses, and their methods of administration. This was evident in the preclinical antimicrobial studies for different set points like explaining better efficacy, and in clinical studies explaining better efficacy or lack of response [19]. 
Vol. 7 No. 2:1 doi: $10.3823 / 0806$
Figure 1: Schematic explanation of the relationship between a hypothetical two antibiotics, concentration versus effects, whether response or toxicity. Note that for any drug concentration point examined for the antibiotic in figure $(A)$, there is wide difference between response and toxicity denoting safer than the hypothetical second antibiotic (B), where a similar drug concentration point examined depicts closer distance between response and toxicity i.e. relatively less safe antibiotic and TDM is a must $[16,17]$.
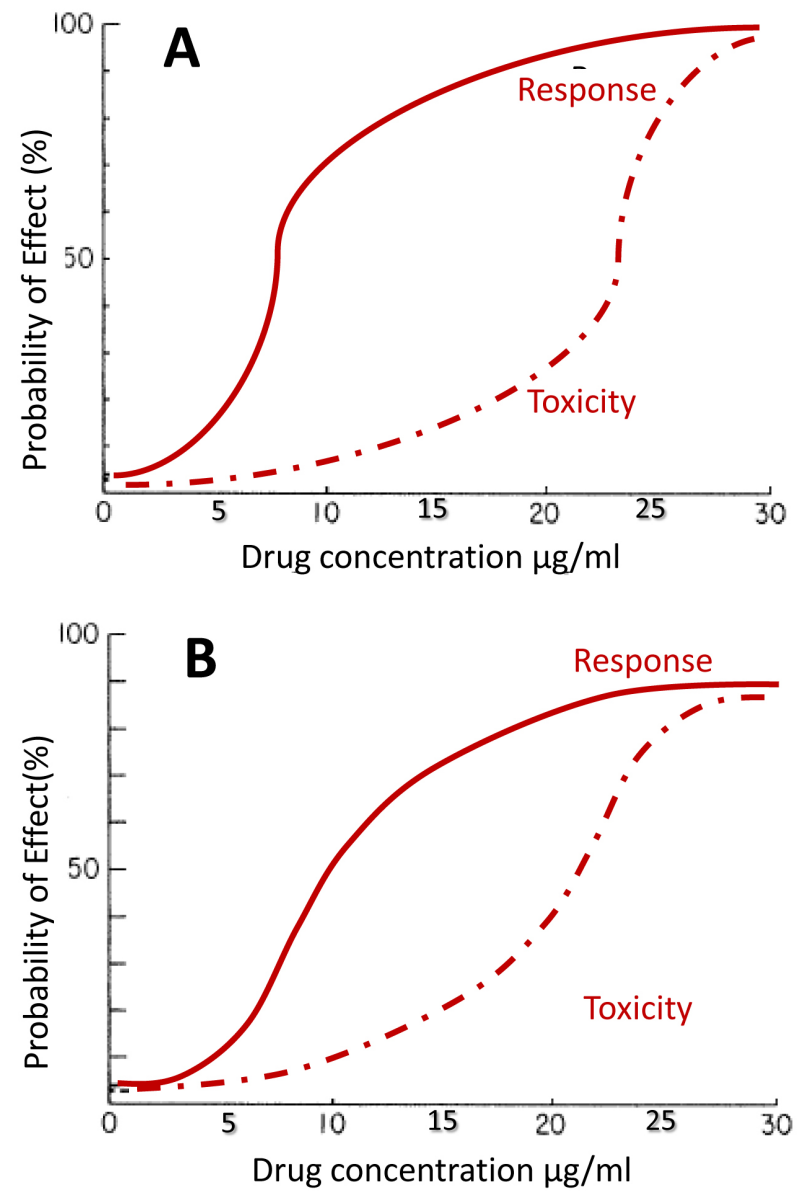

\section{Types of PK/PD bacterial killingand efficacy}

Currently, the known three methods of bacterial killing are: Time dependent, concentration dependent and mixed pattern killing. The free drug component may be the major determinant for efficacy, however, there is "no standardization for pharmacodynamic models that account for the impact of protein binding of antimicrobial agents in vitro" and no consensus about a protein binding model, whether animals or human protein which are used to assess antimicrobial efficacy, and whether in vitro studies apply to in vivo studies [20].

The time dependent bacterial killing (efficacy index $\mathrm{T}>\mathrm{MIC}$, and $f \mathrm{~T}>\mathrm{MIC}$ ) is highly reliable on the duration of attaining sufficient antimicrobial levels above MIC (preferably 4 x MIC) for an established duration of the dosing interval, usually $>40 \%$, with some variations among $\beta$-lactam antibiotics. The concentration dependent bacterial killing (efficacy index $C_{\max } / \mathrm{MIC}$ or $f C_{\max } / \mathrm{MIC}$ ) is related to how highthe administered drug dose level is attained in an individual, without stressing on the duration of drug level above MIC and trough levels, the agents that follow this pattern have a post antibiotic effect (PAE) to span the rest of the dosing interval. The aim is to keep $C_{\max } / \mathrm{MIC}$ target e.g. for aminoglycosides at about 10-12. The mixed pattern bacterial killing (efficacy index AUC/MIC, or $f A U C / M I C)$ is a mix of both above two types of bacterial killing, where both the drug concentration and its duration above MIC for a sufficient duration of time matters, and the target is customized based on the microorganism and infection being treated (Figure 2) [21].

In the animal model, it was evident that the methods of bacterial killing is different for various antimicrobials classes, for some antimicrobials that follow time-dependency ( $\mathrm{T}>\mathrm{MIC}$ ), if studied under different circumstances they fail to show a trustable bacterial killing; taking Ceftobiprole as an example for killing $S$. aureus, where both $C_{\max } / \mathrm{MIC}$ and AUC/MIC did not correlate well as T>MIC, while gatifloxacin, a quinolone that is mostly has a mixed PK/PD bacterial killing pattern (AUC/MIC) fails to do well when tested on T>MIC scale (Figure 3). [19, 22]. The same phenomena are also valid for other 
Figure 2: The PK/PD patterns of bacterial killing. (A) $f T>M I C$ shows the time spent above the antimicrobial MIC for the treated bacteria, (B) $f C m a x / M I C$ which is the maximum concentration an antimicrobial reach over MIC, and (C) fAUC/MIC, a mixed pattern of bacterial killing, it depends on how much antimicrobial was available and its duration above the MIC [21].
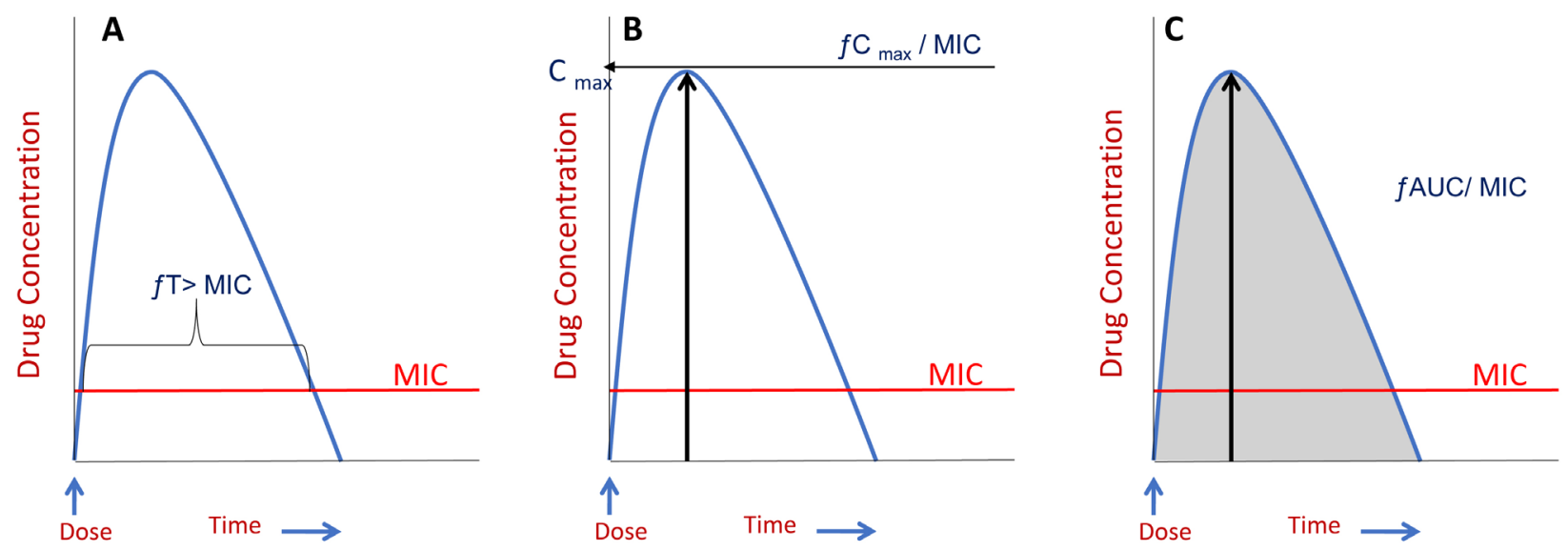

Figure 3: Correlation of ceftobiprole $(A)$ ( $\beta$-Lactam )PK/PD indices with efficacy against a strain of $S$. aureus. Note that the coefficient of determination, shows stronger association for $f \mathrm{~T}>\mathrm{MIC}$, $r^{2}=.85$. Less for the AUC/MIC due to time component and very poor for the Cmax/MIC. Mouse thigh model was used, each circle represent the average of two from both thighs. (B) On the other hand, Salmonella two strains were tested with gatifloxacin, it showed the best activity with $f A U C / M I C$ with, $r^{2}=.94[19,22]$.

\section{A: Ceftobiprole}

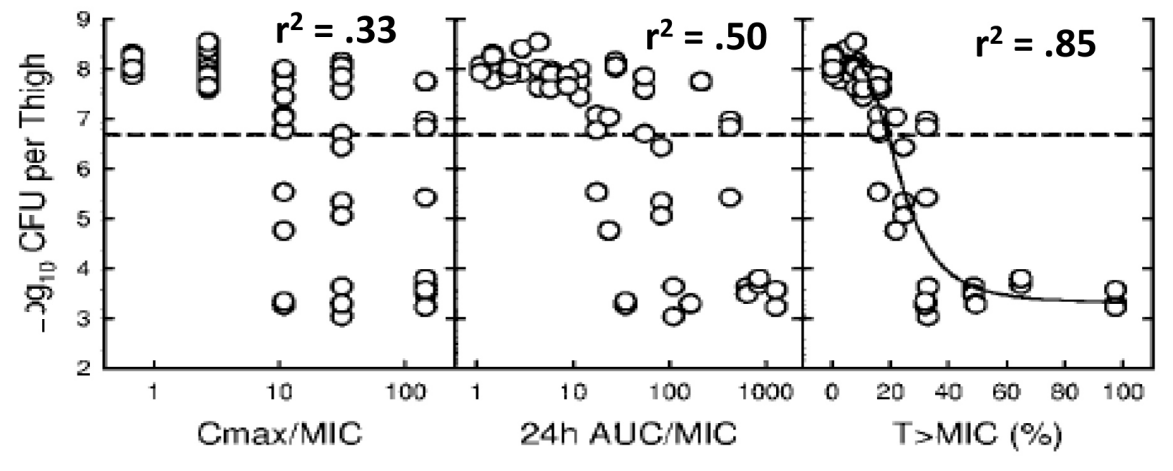

B: Gatifloxacin

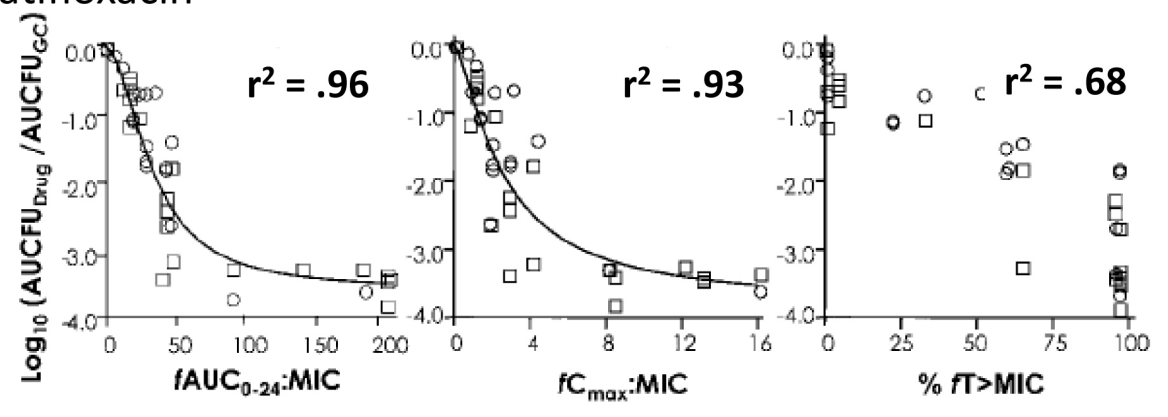


classes of antimicrobials that have concentration dependent kinetics with $f C_{\text {max }} / \mathrm{MIC}$ as the index of activity. A clear example on this killing pattern are Aminoglycosides (Figure 2B), whose attaining high peak levels correlates better with activity, in addition they have post-antibiotic effect (PAE) that bridge the blood absent drug level. Other agents have a similar efficacy index like Fluoroquinolones, Daptomycin, GLycopeptides, Amphotericin B, and Echinocandins [23]. The third type of PK/PD bacterial killing is the mixed pattern, and that is dependent on both attaining a sufficient concentration for a sufficient time above the antimicrobial MIC, examples are Fluoroquinolones, Daptomycin, GLycopeptides, Ketolides, Macrolides, Clindamycin, Streptogramins, Oxazolidonoes, Tetracyclines, Glycycyclines, Aminoglycosides, Triazoles, and Echinocandins (Figure 2C) [24].

\section{Clinical correlate of PK/PD and its applicationin septic patients}

Physicochemical properties of antimicrobials and dosage requirements in the presence of severe sepsis in critically sick patients do matter, the concentration of the "hydrophilic" antimicrobials like aminoglycosides, $\beta$-lactams, GLycopeptides and Lipopeptides are highly extracellularly distributed, the interplay of many factorsmay cause antimicrobials to be increased or decreasedinearly sepsis-induced augmented clearance or decreased renal clearance due to AKI respectively, and dosages need to be adjusted accordingly. However, "lipophilic" antimicrobials like tetracyclines, fluoroquinolones, glycylcyclines, ketolides, macrolides, metronidazole, streptogramins, are all highly intracellularly distributed and predominantly hepatically cleared, and their dose modification is marginal to non $[25,26,27]$.

In $\beta$-lactams-treated animal model, S. pneumoniae infected animals demonstratedimproved survival as T>MIC attain higher than $40 \%$ of dosing interval target. Human clinical trials on antimicrobials in the treatment of critically septic patients applying
PK/PD were reported. PK/PD parameters proved in human to work well for T>MIC in otitis media model, where the correlation of the target attainment and cure when using penicillin to treat $S$. pneumoniae and $H$. influenzae was evident, and cure of more than $80 \%$ of patients occurred in whom $\geq$ $40 \%$ target was attained [28]. The same phenomena were evident with the 24 hours AUC/MIC when target attained over $125 \mathrm{mg}$.hr/Lhas been met on treating gram-positive and gram-negative bacteria. Daptomycin was also evaluated in critically septic patients with shock and high SOFA scoresdue to MRSA bacteremia. Significantly lower daptomycin exposures were observed despite comparable doses in a subset of patients with augmented clearance, and the probability of target attainment was not achieved in all patients. In-hospital mortality was significantly higher (30.7\% vs $10.8 \%$ ) in patients with augmented daptomycin clearance [29]. Also, Vancomycin standard dosages did not achieve the PK/PD target $\left(\mathrm{AUC}_{24} / \mathrm{MIC}\right)$ in about $33 \%$ of patients treated for MRSA bacteremia, in the absence of RRT, cardiac surgery and malignancy [30]. In patients with infective endocarditis, including left- and right-sided, a retrospective study focusing on day 1PK/PD of vancomycin $\mathrm{AUC}_{0-24} / \mathrm{MIC}$ showed that target of $\leq 600 \mathrm{mg} . \mathrm{hr} / \mathrm{L}(\mathrm{P}=.047)$ was associated with treatment failure, and not as reported earlier of $400 \mathrm{mg} \cdot \mathrm{hr} / \mathrm{L}$ [31].

A prospective, multinational pharmacokinetic point-prevalence study including $8 \beta$-lactam antibiotics. Two blood samples were taken from each patient during a single dosing interval. The primary PK/PD targets were free antibiotic concentrations above the MIC of the pathogen at both 50\% (50\% $f \mathrm{~T}>\mathrm{MIC})$ and $100 \%(100 \% \mathrm{fT}>\mathrm{MIC})$ of the dosing interval. The study found positive clinical outcome associated with increasing 50\% fT >MIC and 100\% $f \mathrm{~T}>\mathrm{MIC}$ ratios $(\mathrm{OR}, 1.02$ and 1.56 , respectively; $\mathrm{P}$ $<.03)$, with significant interaction with sickness severity status. The results suggested that ICU clini- 
cians mustcustomize dosing strategies for the critically sick patients due to $\beta$-lactams significant PK variability, to assure drug target exposure and to optimize the outcome of the treated patients [32].

Moreover, another advantage of adequate target attainment in septic patient is the prevention of mutant selection due to antimicrobials under exposure, knowingly that bacterial population causing sepsis are mostly heterogenous in their antimicrobial susceptibility with higher MIC-mutants $[33,34]$, mutant bacteria with elevated MIC need higher antimicrobial doses to overcome the mutant selection "window" (MSW), and to bridge the gap to the "novel" target as a PK/PDefficacy index (Figure 4) [34, 35].

\section{Intermittent versus continuous infusion $\beta$-lactam}

The administration of antimicrobials is customarily given as intermittent bolus (IB) in most of the hospitals worldwide, and probably all ICUs of our region because the continuous infusion $(\mathrm{Cl})$ method is considered not practical, and not accepted as the standard of care in our region (personal knowledge). However, several studies were conducted comparing clinical efficacy of $\mathrm{CI}$ versus IB as a surrogate for the probability of target attainment (PTA) as PK/PD efficacy index. A Monte Carol Simulationbased study for standard doses of the $\beta$-lactams (ceftobiprole, meropenem, piperacillin/tazobactam and cefepime) whether they reach $>50 \% f \mathrm{~T}>\mathrm{MIC}$ and to achieve $>0.9$ PTA, only $\mathrm{Cl}$ and/or high doses IB were required [36]. In a multicenter survey study performed to describe the various approaches used for $\beta$-lactam TDM in ICUs, different PK/PD target attainments were reached through different dosing methods; continuous infusion $(\mathrm{Cl})$ versus intermittent bolus (IB) when $f \mathrm{~T}>4 \times \mathrm{MIC}$ was $100 \%$ for $\mathrm{Cl}$ and ranged $40-70 \%$ for IB [37]. Another multicenter PK/PD study comparing $\mathrm{Cl}$ versus IB of $\beta$-lactam demonstrated that antimicrobial level above MIC (T>MIC) was significantly achieved for $\mathrm{Cl}(82 \%$ versus $29 \%, \mathrm{P}=.001)$ with higher clinical cure rate $(70 \%$ versus $43 \% \mathrm{P}=.037)$, but there was no difference in the secondary endpoint of ICU free days or survival by hospital discharge

Figure 4: The PK/PD patterns of bacterial killing, note the elevated MIC for mutant bacteria (Mutant prevention concentration (MPC), which made less antimicrobial exposure for the three PK/ PD indices. (A) $f T>M P C$ shows the time spent above the antimicrobial MPC for the treated bacteria, (B) $f$ Cmax/MPC which is the maximum concentration an antimicrobial reach over MPC, and (C) fAUC/MPC. The preferable many folds above MIC for T>MPC is difficult to attain with regular antimicrobial doses, and the same for the other two PK/PD indices. MSW: mutant selection window [34, 35].
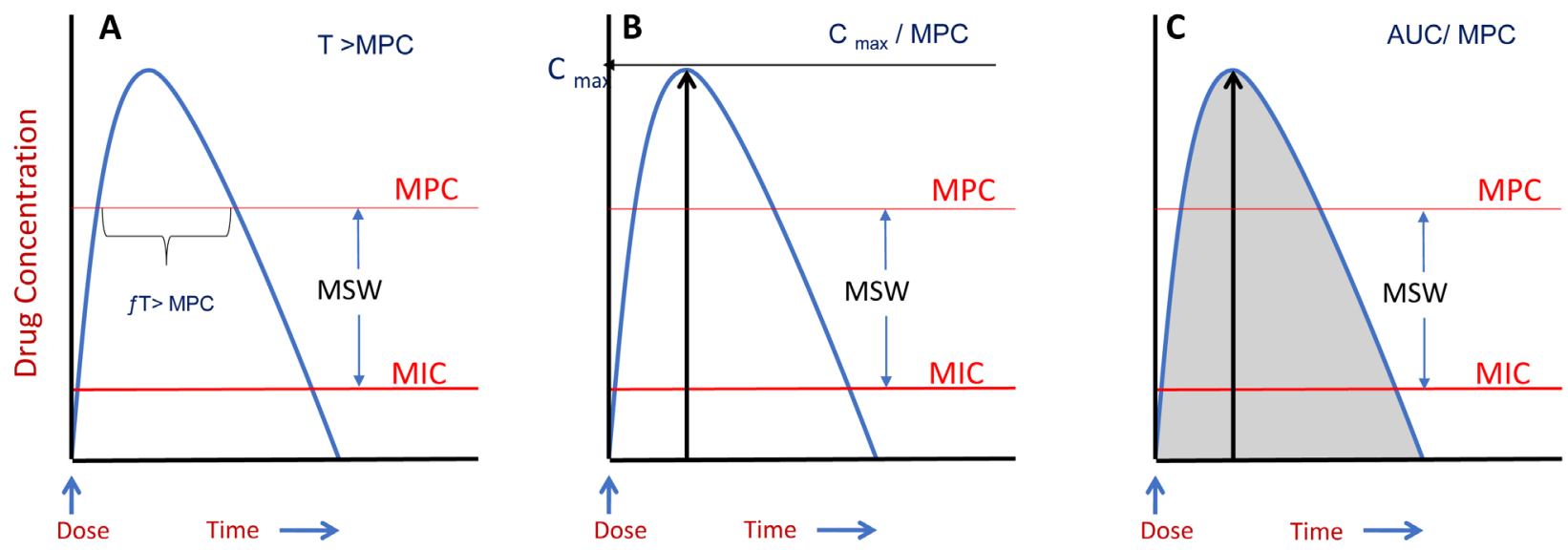
[38]. In a succeeding clinical trial in critically septic patients evaluating the endpoint of the number of alive ICU-free days at Day 28, and secondary endpoints of 90-day survival, clinical cure 14 days post antibiotic cessation, alive organ failure-free days at Day 14, and duration of bacteremia, there was no difference in the measured endpoints between $\mathrm{Cl}$ or IBß-lactam infusion [39]. A two-center study and 140 patients equally assigned in critically ill patients with severe sepsis not receiving RRT, Cl versus IB demonstrated higher clinical cure rates (56 versus $34 \%, p=0.011$ ) and had better PK/ PD target attainment (97 versus $70 \%, p<0.001$ ). Continuous $\beta$-lactam infusion may be mostly advantageous for critically ill patients with high severity scores and not receiving RRT [40].

A meta-analysis by J.A. Roberts and his group identified three clinical trials on $\beta$-Lactam in Severe Sepsis, $C$ I versus IB, with 632 patients, there was no difference in clinical cure rates after adjustment for other covariates by multivariate analysis, however borderline significance of decreased mortality in the $\mathrm{Cl}$ group $(\mathrm{P}=0.045)$ was observed [41]. Linezolid was administered as IB versus $\mathrm{Cl}$, the $\mathrm{Cl}$ gave an earlier and stable steady state level above the treated bacterial MIC with significantly achieving the target AUC/MIC ( $P<0.05)$ at $80-120$, though both groups did not differ significantly in the clinical response, probably due to small number of patients recruited for the study [42].

So far, there is not sufficient convincing evidence to recommend wide scale use of $\mathrm{Cl}$; no differences in mortality, infection recurrence, clinical cure, super-infection post-therapy, and safety outcomes were similar. Cl strategy may be employed in some clinical scenarios like in critically sick patients with severe infections, with normal renal function and lung infections, and with resistant pathogens. Still questions on $\mathrm{Cl}$ of $\beta$-lactams need to be answered, like the effect of $\mathrm{Cl}$ when there are additional confounders, RRT and renal failure, and various organs infections. Additional large sample size prospective randomized trials are needed, utilizing PK/PD principles and focusing on special categories of patients, being on ventilator or not, having only sepsis, sepsis with shock, MODS, gram-positive versus gram-negative bacteria, and the level of bacterial MICs [43].

\section{PK/PD principles of antimicrobials dosing when dealing withBiofilm}

A biofilm is a structured consortium of bacteria embedded in a self-produced polymer matrix consisting of polysaccharide, protein and extracellular DNA. Bacterial biofilms are resistant to antibiotics, disinfectant chemicals and to phagocytosis and other components of the innate and adaptive inflammatory defense system of the body." [44]. Biofilm is usually produced by sessile bacteria, and it can be produced on the surfaces of the host tissues and the embedded prosthetic materials in human tissues $[45,46]$. However, the same patterns of bacterial killing hold true for sessile as in planktonic bacteria, whether time dependency ( $\mathrm{T}>\mathrm{MIC}$ ), concentration dependency (Cmax/MIC) ormixed patterns (AUC/MIC), nonetheless, higher antimicrobial levels are needed, where mature biofilm require remarkably higher levels of antimicrobials than a young biofilm. PK/PD indices here are being dealt as related to $T>$ Minimum biofilm inhibition concentration ( $\mathrm{T}>\mathrm{MBIC}$ ) and $\mathrm{T}>$ minimum biofilm eradication concentration (T>MBEC), Cmax/MBIC and (max/MBEC), and AUC/MBIC and $A U C / M B E C$ are probably the targets for dosing with respected antimicrobials according to type of killing, but so far in vivo studies are lacking, probably antimicrobials with wide TI are candidates [47]. In addition to the known bacterial killing index of imipenem (T>MBIC) for biofilm bacteria, an interesting phenomenon for imipenem as a $\beta$-lactam is that "the AUC/MIC of imipenem showed a better correlation with the efficacy for biofilm infections $\left(R^{2}=0.89\right)$ than planktonic cell infections $\left(R^{2}=\right.$ $0.38)^{\prime \prime}$ when was used to treat Pseudomonas aeruginosa strain in a mouse lung model, it behaved 
like colistin that follow AUC/MIC, this phenomena needs further clarification in future in vitro and in vivo studies, [48]. Another notion in some reports is that using combination antimicrobials to treat infections with established biofilm may be more effective than the use of a mono-active antimicrobial agent, in an in vitro study based on biofilms recovered from patients with infected joints, azithromycin in combination with daptomycin was found more effective than either one alone [49], other antibiotics behaved the same when used as monotherapy, showing advantage for combination when using biofilm active agent, and rifampin was the most active agent against biofilms when used in combination [50]. Agents that directly work on biofilms are under development, in the future, antibiofilm agents may be used alongside as standard anti-infective agents in combating all types of prosthetic devices [51].

In conclusion, the evolving field of PK/PD in the treatment of critically septic patients is still looking for clear answers from in vivo studies; to define targets for different infections, microorganisms and antimicrobial agents, to delineate better, which groups of patients benefit more of continuous infusion compared with intermittent bolus dose strategy. To recommend what differently it can be done for the prosthetic devices infections with established biofilms, and to demonstrate a clear PK/PD-dependent clinical data focusing on better recovery, survival, cost containment and long-term prognosis.

\section{Acknowledgement}

This article was presented as a plenary lecture in Manama, Bahrain "The second annual infectious diseases conference, Wednesday (April 5), ART Rotana Hotel and Resort, Amwaj Islands."

\section{References}

1. Alberti C, Brun-Buisson C, Burchardi H, Martin C, Goodman S, Artigas A, Sicignano A, Palazzo M, Moreno R, Boulmé R, Lepage $E$. Epidemiology of sepsis and infection in ICU patients from an international multicentre cohort study. Inten Care Med 2002; 28(2):108-21.

2. Vincent JL, Sakr Y, Sprung $C L$, Ranieri VM, Reinhart $K$, Gerlach H, Moreno R, Carlet J, Le Gall JR, Payen D, Sepsis Occurrence in Acutely III Patients Investigators. Sepsis in European intensive care units: results of the SOAP study. Crit Care Med 2006; 34(2):344-53.

3. Angus DC, Linde-Zwirble WT, Lidicker J, Clermont G, Carcillo J, Pinsky MR. Epidemiology of severe sepsis in the United States: analysis of incidence, outcome, and associated costs of care. Crit Care Med 2001; 1; 29(7):1303-10.

4. Finfer S, Bellomo R, Lipman J, French C, Dobb G, Myburgh J. Adult-population incidence of severe sepsis in Australian and New Zealand intensive care units. Inten Care Med 200; 30(4):589-96.

5. RENAL Replacement Therapy Study Investigators. Intensity of continuous renal-replacement therapy in critically ill patients. N Engl J Med. 2009; 22: 1627-38.

6. Dombrovskiy VY, Martin AA, Sunderram J, Paz HL. Rapid increase in hospitalization and mortality rates for severe sepsis in the United States: a trend analysis from 1993 to 2003. Crit Care Med 2007; 1; 35(5):1244-50.

7. EPISEPSIS Study Group. EPISEPSIS: a reappraisal of the epidemiology and outcome of severe sepsis in French intensive care units. Intensive Care Med 2004; 30(4):580-8.

8. Gaieski DF, Mikkelsen ME, Band RA, Pines JM, Massone R, Furia FF, Shofer FS, Goyal M. Impact of time to antibiotics on survival in patients with severe sepsis or septic shock in whom early goaldirected therapy was initiated in the emergency department. Crit Care Med 2010; 38(4):1045-53.

9. Liu VX, Fielding-Singh V, Greene JD, Baker JM, Iwashyna TJ, Bhattacharya J, Escobar GJ. The timing of early antibiotics and hospital mortality in sepsis. Am J Respir Crit Care Med 2017; doi: 10.1164/rccm.201609-18480C

10. Ferrer R, Martin-Loeches I, Phillips G, Osborn TM, Townsend S, Dellinger RP, Artigas A, Schorr C, Levy MM. Empiric antibiotic treatment reduces mortality in severe sepsis and septic shock from the first hour: results from a guideline-based performance improvement program. Crit Care Med 2014; 42(8):1749-55.

11. Kumar A, Ellis $P$, Arabi $Y$, Roberts $D$, Light $B$, Parrillo JE, Dodek $P$, Wood G, Kumar A, Simon D, Peters C. Initiation of inappropriate antimicrobial therapy results in a fivefold reduction of survival in human septic shock. Chest 2009; 136(5):1237-48.

12. Jones ME, Karlowsky JA, Draghi DC, Thornsberry C, Sahm DF, Nathwani D. Epidemiology and antibiotic susceptibility of bacteria causing skin and soft tissue infections in the USA and Europe: a guide to appropriate antimicrobial therapy. Int J Antimicrob Agents 2003; 31:22(4):406-19. 
13. Brun-Buisson C, Doyon F, Carlet J. Bacteremia and severe sepsis in adults: a multicenter prospective survey in ICUs and wards of 24 hospitals. French Bacteremia-Sepsis Study Group. Am J Respir Crit Care Med 1996; 154(3):617-24.

14. Shah S, Barton G, Fischer A. Pharmacokinetic considerations and dosing strategies of antibiotics in the critically ill patient. J Intensive Care Society. 2015; 16(2):147-53.

15. Philips BJ, Lane K, Dixon J, MacPhee I. The effects of acute renal failure on drug metabolism. Expert Opin Drug Metab Toxicol 2014; 1; 10(1):11-23.

16. Evans WE, Schentag JJ, Jusko WJ, editors. Applied pharmacokinetics: principles of therapeutic drug monitoring. Applied Therapeutics, Incorporated; 1992.

17. Roberts JA, Lipman J. Pharmacokinetic issues for antibiotics in the critically ill patient. Crit Care Medi 2009; 37(3):840-51.

18. Sime FB, Roberts MS, Peake SL, Lipman J, Roberts JA. Does beta-lactam pharmacokinetic variability in critically ill patients justify therapeutic drug monitoring? A systematic review. Ann Intensive Care 2012; 2(1):35.

19. Ambrose PG, Bhavnani SM, Rubino CM, Louie A, Gumbo T, Forrest A, Drusano GL. Pharmacokinetics-pharmacodynamics of antimicrobial therapy: it's not just for mice anymore. Clin Infect Dis 2007; 44(1):79-86.

20. Zeitlinger MA, Derendorf H, Mouton JW, Cars O, Craig WA, Andes D, Theuretzbacher U. Protein binding: do we ever learn?. Antimicrob Agents Chemother 2011; 55(7):3067-74.

21. Toutain PL, Del Castillo JR, Bousquet-Mélou A. The pharmacokinetic-pharmacodynamic approach to a rational dosage regimen for antibiotics. Res Vet Sci 2002; 73(2):105-14.

22. Craig WA, Andes DR. In vivo pharmacodynamics of ceftobiprole against multiple bacterial pathogens in murine thigh and lung infection models. Antimicrob Agents Chemother 2008; 52(10):3492-6.

23. Karlowsky JA, Zhanel GG, Davidson RJ, Hoban DJ. Once-daily aminoglycoside dosing assessed by MIC reversion time with Pseudomonas aeruginosa. Antimicrob Agents Chemother 1994; 38(5):1165-8.

24. Van Bambeke F. Macrolides and ketolides. InFundamentals of antimicrobial pharmacokinetics and pharmacodynamics 2014 (pp. 257-278). Springer New York.

25. Blot SI, Pea F, Lipman J. The effect of pathophysiology on pharmacokinetics in the critically ill patient-concepts appraised by the example of antimicrobial agents. Adv Drug Deliv Rev 2014 Nov 20; 77:3-11

26. Gomez H, Ince C, De Backer D, Pickkers P, Payen D, Hotchkiss J, Kellum JA. A unified theory of sepsis-induced acute kidney injury: inflammation, microcirculatory dysfunction, bioenergetics and the tubular cell adaptation to injury. Shock (Augusta, Ga.) 2014; 41(1):3.
27. Udy AA, Baptista JP, Lim NL, Joynt GM, Jarrett P, Wockner L, Boots RJ, Lipman J. Augmented renal clearance in the ICU: results of a multicenter observational study of renal function in critically ill patients with normal plasma creatinine concentrations. Cri Care Med 2014; 42(3):520-7.

28. Craig WA. Pharmacokinetic/pharmacodynamic parameters: rationale for antibacterial dosing of mice and men. Clin Infect Dis 1998; 26(1):1-0.

29. Falcone M, Russo A, Venditti M, Novelli A, Pai MP. Considerations for higher doses of daptomycin in critically ill patients with methicillin-resistant Staphylococcus aureus bacteremia. Clin Infect Dis 2013; 57(11):1568-76.

30. de Gatta MD, Revilla N, Calvo MV, Domínguez-Gil A, Navarro AS. Pharmacokinetic/pharmacodynamic analysis of vancomycin in ICU patients. Intensive Care Med 2007; 33(2):279-85.

31. Casapao AM, Lodise TP, Davis SL, Claeys KC, Kullar R, Levine DP, Rybak MJ. Association between vancomycin day 1 exposure profile and outcomes among patients with methicillin-resistant Staphylococcus aureus infective endocarditis. Antimicrob Agents Chemother 2015; 59(6):2978-85.

32. Roberts JA, Paul SK, Akova M, Bassetti M, De Waele JJ, Dimopoulos G, Kaukonen KM, Koulenti D, Martin C, Montravers P, Rello J. DALI: defining antibiotic levels in intensive care unit patients: are current $\beta$-lactam antibiotic doses sufficient for critically ill patients?. Clin nfect Dis 2014; 58(8):1072-83.

33. Olofsson SK, Cars O. Optimizing drug exposure to minimize selection of antibiotic resistance. Clin Infect Dis 2007; 45 (Supplement 2):S129-36.

34. Abdul-Aziz MH, Lipman J, Mouton JW, Hope WW, Roberts JA. Applying pharmacokinetic/pharmacodynamic principles in critically ill patients: optimizing efficacy and reducing resistance development. In Seminars in respiratory and critical care medicine 2015 Feb (Vol. 36, No. 01, pp. 136-153). Thieme Medical Publishers.

35. Drusano GL, Johnson DE, Rosen $M$, Standiford $H C$. Pharmacodynamics of a fluoroquinolone antimicrobial agent in a neutropenic rat model of Pseudomonas sepsis. Antimicrob Agents Chemother 1993; 37(3):483-90.

36. Zelenitsky SA, Ariano RE, Zhanel GG. Pharmacodynamics of empirical antibiotic monotherapies for an intensive care unit (ICU) population based on Canadian surveillance data. J Antimicrob chemother 2011; 66(2):343-9.

37. Wong G, Brinkman A, Benefield RJ, Carlier M, De Waele JJ, El Helali N, Frey O, Harbarth S, Huttner A, McWhinney B, Misset B. An international, multicentre survey of $\beta$-lactam antibiotic therapeutic drug monitoring practice in intensive care units. J Antimicrob chemother 2014; 69(5):1416-23.

38. Dulhunty JM, Roberts JA, Davis JS, Webb SA, Bellomo R, Gomersall C, Shirwadkar C, Eastwood GM, Myburgh J, Paterson DL, Lipman J. Continuous infusion of beta-lactam antibiotics in severe sepsis: a multicenter double-blind, randomized controlled trial. Clin Infect Dis 2013; 56(2):236-44. 
39. Dulhunty JM, Roberts JA, Davis JS, Webb SA, Bellomo R, Gomersall C, Shirwadkar C, Eastwood GM, Myburgh J, Paterson $\mathrm{DL}$, Starr T. A multicenter randomized trial of continuous versus intermittent $\beta$-lactam infusion in severe sepsis. Am J Respir Crit Care Med 2015; 192(11):1298-305.

40. Abdul-Aziz MH, Sulaiman $H$, Mat-Nor MB, Rai $V$, Wong KK, Hasan MS, Rahman AN, Jamal JA, Wallis SC, Lipman J, Staatz CE. Beta-Lactam Infusion in Severe Sepsis (BLISS): a prospective, two-centre, open-labelled randomised controlled trial of continuous versus intermittent beta-lactam infusion in critically ill patients with severe sepsis. Intensive Care Med 2016; 42(10):1535-45.

41. Roberts JA, Abdul-Aziz MH, Davis JS, Dulhunty JM, Cotta MO, Myburgh J, Bellomo R, Lipman J. Continuous versus Intermittent $\beta$-Lactam Infusion in Severe Sepsis. A Meta-analysis of Individual Patient Data from Randomized Trials. Am J Respir Crit Care Med 2016; 194(6):681-91.

42. Adembri C, Fallani S, Cassetta MI, Arrigucci S, Ottaviano A, Pecile P, Mazzei T, De Gaudio R, Novelli A. Linezolid pharmacokinetic/ pharmacodynamic profile in critically ill septic patients: intermittent versus continuous infusion. Int J Antimicrob Agents. 2008; 31(2):122-9.

43. Shiu JR, Wang E, Tejani AM, Wasdell M. Continuous versus intermittent infusions of antibiotics for the treatment of severe acute infections. The Cochrane Library. 2013 Jan 1.

44. Høiby N, Ciofu O, Johansen HK, Song ZJ, Moser C, Jensen PØ, Molin S, Givskov M, Tolker-Nielsen T, Bjarnsholt T. The clinical impact of bacterial biofilms. Int J Oral Sci 2011; 3(2):55.

45. Høiby N, Bjarnsholt T, Moser C, Bassi GL, Coenye T, Donelli G, Hall-Stoodley L, Holá V, Imbert C, Kirketerp-Møller K, Lebeaux D. ESCMID guideline for the diagnosis and treatment of biofilm infections 2014. Clin Microbial Infect 2015; 21:S1-25.

46. Ribet $D$, Cossart $P$. How bacterial pathogens colonize their hosts and invade deeper tissues. Microbes Infect 2015; 17(3):173-83.

47. Hengzhuang W, Wu H, Ciofu O, Song Z, Høiby $N$. Pharmacokinetics/pharmacodynamics of colistin and imipenem on mucoid and nonmucoid Pseudomonas aeruginosa biofilms. Antimicrob Agents Chemother 2011; 55(9):4469-74.
48. Hengzhuang W, Wu H, Ciofu O, Song Z, Høiby N. In vivo pharmacokinetics/pharmacodynamics of colistin and imipenem in Pseudomonas aeruginosa biofilm infection. Antimicrob Agents Chemother 2012; 56(5):2683-90.

49. Parra-Ruiz J, Bravo-Molina A, Peña-Monje A, Hernández-Quero J. Activity of linezolid and high-dose daptomycin, alone or in combination, in an in vitro model of Staphylococcus aureus biofilm. J Antimicrob Chemother 2012; 13:dks272.

50. Saginur R, StDenis M, Ferris W, Aaron SD, Chan F, Lee C, Ramotar K. Multiple combination bactericidal testing of staphylococcal biofilms from implant-associated infections. Antimicrob Agents Chemother 2006; 50(1):55-61.

51. de la Fuente-Núñez C, Reffuveille F, Fernández L, Hancock RE. Bacterial biofilm development as a multicellular adaptation: antibiotic resistance and new therapeutic strategies. Curr Opin Microbiol 2013; 16(5):580-9.

\section{Publish in The International Arabic Journal of Antimicrobial Agents}

The Journal is an open access peer-reviewed journal that publishes scientific papers about all aspects of antimicrobials. The journal will publish original research articles, reviews, brief reports and case reports dealing with basic and clinical antibacterial agents, antiviral, antiprotozoals, antituberculuous, antifungal and antihelminthes agents. All manuscripts must be prepared in English, and are subject to a rigorous and fair peer-review process. Accepted papers will immediately appear online. The journal aims to advance the knowledge, attitude and the research of chemotherapy in the Arabic world in cooperation with international, national scientific and public societies as well as research centers with similar aims and objectives. 